cabo de vassoura na vagina dela no mesmo dia que a vítima foi sepultada. $\mathrm{O}$ acusado se encontrava embriagado e foi visto com uma garrafa de aguardente durante o sepultamento da vítima. No meio policial e entre os moradores de sua cidade era conhecido como necrófilo e tinha o hábito de violentar cadáveres homens. Ao delegado de polícia, o acusado confessou o delito e disse que tinha atração sexual por pessoas mortas e que poderiam ser homens ou mulheres, não importava a idade, e que não se sentia atraído por pessoas vivas. Havia sido preso anteriormente por ter abusado sexualmente de um homem e uma mulher falecidos e, inclusive, praticou sexo anal com o cadáver masculino. Sentia-se muito

\section{Necrofilia: uma rara parafilia} Necrophilia: a rare paraphilia

Caro Editor,

Desejo trazer a conhecimento o caso de BGL, 49 anos, solteiro, sexo masculino, aposentado e interno do Hospital de Custódia e Tratamento Psiquiátrico de Franco da Rocha-SP. Segundo consta no inquérito policial, ele violou uma sepultura e vilipendiou o cadáver de uma mulher de 82 anos de idade introduzindo um excitado sexualmente diante de um cadáver e se masturbava. Os irmãos relataram que o interno não conseguiu ter aprendizagem na escola e nem trabalhar ou ter vida socioeconômica independente. Aos 15-16 anos de idade furtou algumas vezes caixões de crianças de uma funerária, colocava-os na sala de sua casa, chamava as pessoas para um velório e então se descobria que os caixões estavam vazios. Houve menção de que tentava violentar o cadáver de uma pessoa que the provocava raiva quando viva. Em casa era calmo e cooperativo, não ingeria bebida alcoólica de modo frequente $\mathrm{e}$ nem usava drogas. Tinha tendência para homossexualidade e nunca teve namoradas. Quando jovem, teria sido violentado sexualmente por outro homem. Anteriormente, não se submeteu a tratamento 
psiquiátrico de forma regular. O exame físico revelou dismorfia da face, biotipo displásico e obesidade. $\mathrm{O}$ exame psíquico revelou déficit de inteligência como transtorno significativo em associação com perversão sexual.

Necrofilia é uma rara e bizarra parafilia caracterizada por atração e gratificação sexual por pessoas mortas ${ }^{1}$. Richard Von KrafftEbing é considerado um dos primeiros cientistas interessados em comportamentos sexuais anormais e, em 1886, ele considerava necrofilia como um comportamento perverso e que poderia ser decorrente de condiçôes "neuropáticas ou psicopáticas", como senilidade ou enfraquecimento mental adquirido ${ }^{2}$. O caso relatado é congruente com a descrição de enfraquecimento mental e esta perversão sexual.

A literatura mais antiga associava necrofilia com severa psicopatologia. Desrosières analisou 53 observaçôes de casos descritos e encontrou 19\% de debilidade mental, 13\% de problemas neuróticos, 7,5\% de epilepsia, 5,5\% de depressão e $4 \%$ de psicose $\mathrm{e}^{3}$. Estas observações são concordantes com o caso relatado (presença de severa psicopatologia e retardo mental).

Rosman e Resnick revisaram 122 casos de necrofilia, classificando-os em três tipos (homicídio necrofílico, necrofilia regular e fantasia necrofílica), e descobriram que 11\% dos necrófilos genuínos mostraram evidência de psicose. Álcool foi considerado um fator importante para vencer a inibição e cometer o ato (especialmente no grupo homicida), mas o diagnóstico mais comum foi transtorno de personalidade (metade da amostra $)^{4}$. O uso de álcool contribuiu para o delito ocorrido no caso relatado e se mostrou congruente com a revisão desses autores.

Anil Aggrawal propôs uma nova classificação para necrofilia: pseudonecrofilia (uma pessoa finge estar morta), necrófilo romântico, necrófilos platônicos ou fantasias necrófilas, necrófilos táteis, necrofilia fetichista, necromutilomania, necrófilos oportunistas, necrófilos regulares, necrófilos homicidas e necrófilos exclusivos $^{5}$. O caso relatado preenche critérios diagnósticos para necrofilia em associação com retardo mental moderado e abuso de álcool e pode ser considerado um necrófilo regular ou também chamado "necrófilo clássico" (preferência por contatos sexuais com pessoas mortas, embora possa ter contatos sexuais com pessoas vivas e mortas).

Roberto Moscatello

Hospital de Custódia e Tratamento Psiquiátrico Professor André Teixeira Lima, Franco da Rocha, SP, Brasil

\section{Financiamento e conflito de interesse}

\begin{tabular}{|c|c|c|c|c|c|c|c|}
\hline $\begin{array}{l}\text { Membro do grupo } \\
\text { de autores }\end{array}$ & $\begin{array}{l}\text { Local de } \\
\text { trabalho }\end{array}$ & $\begin{array}{l}\text { Verba de } \\
\text { pesquisa }^{1}\end{array}$ & $\begin{array}{c}\text { Outro apoio à } \\
\text { pesquisa ou educação } \\
\text { médica continuada }\end{array}$ & $\begin{array}{l}\text { Honorários } \\
\text { de } \\
\text { palestrantes }\end{array}$ & $\begin{array}{l}\text { Participação } \\
\text { acionária }\end{array}$ & $\begin{array}{l}\text { Consultorl } \\
\text { conselho } \\
\text { consultivo }\end{array}$ & Outro $^{3}$ \\
\hline Roberto Moscatello & HCTP & - & - & - & - & - & - \\
\hline $\begin{array}{l}\text { Modesto } \\
\text { * Significativa } \\
\text { ** Significativa. Montar } \\
\text { Vota: HCTP = Hospital } \\
\text { Mais informacões cons }\end{array}$ & $\begin{array}{l}\text { necidos } \\
\text { tódia e } T \\
\text { Instrucõ }\end{array}$ & $\begin{array}{l}\text { tuição do } \\
\text { nento Psiq } \\
\text { sAutores. }\end{array}$ & $\begin{array}{l}\text { or ou a colega onde o a } \\
\text { rico Professor André Te }\end{array}$ & $\begin{array}{l}\text { em participaç } \\
\text { a Lima. }\end{array}$ & er & o autor. & \\
\hline
\end{tabular}

Referências

1. Hucker JS, Stermac L. The evaluation and treatment of sexual violence, necrophilia and asphyxiophilia. Psychiatr Clin North Am. 1992;15(3):70319.

2. Burg BK. The sick and the dead: the development of psychological theory on necrophilia from Krafft-Ebing to the present. J Hist Behav Sci. $1982 ; 18(3): 242-54$.
3. Tridon P, Crombez Y, Vidailhet C, Paugain M, Boissemin JM. A propos d'un cas de nécrophilie approche structurale et psychophatologique. Ann Med Psychol (Paris). 1984;142(7):1017-24.

4. Rosman JP, Resnick PJ. Sexual attraction to corpses: a psychiatric review of necrophilia. Bull Am Acad Psychiatry Law. 1989;17(2):153-63.

5. Aggrawal A. A new classification of necrophilia. J Forensic Leg Med. 2009;16(6):316-20. 